\title{
Gambaran kesejahteraan psikologi terhadap kepatuhan manajemen diri pasien hemodialisa
}

\author{
Erna Melastuti ${ }^{1 *}$, Indah Sri Wahyuningsih ${ }^{2}$ \\ ${ }^{1,2}$ Fakultas IImu Keperawatan, Universitas Islam Sultan Agung, Indonesia \\ *Coresponding Author: erna@unissula.ac.id
}

\begin{abstract}
Abstrak
Pendahuluan: Hemodialisis adalah kondisi yang kronis membutuhkan manajemen diri yang sangat relevan. Manajemen diri terkait kepatuhan yang buruk merupakan masalah yang luas pada pasien dengan hemodialisis dan menyebabkan konsekuensi berat untuk pasien, bahkan kematian. Tujuan dari penelitian ini adalah untuk mengetahui gambaran Psychology well being pasien hemodialisis terhadap kepatuhan manajemen terapi pasien hemodialisis. Metode: yang digunakan dalam penelitian ini adalah deskriptif analitik dengan melihat bagaimana psychological well being pasien serta kepatuhan managemen diri yang dilaksanakan pasien. Instrumen yang digunakan yaitu Psychological Well Being Questionare, Renal Adherence Attitudes Questionnaire (RAAQ) And Renal Adherence Behaviour Questionnaire (RABQ). Hasil: uji statistik menggunakan Spearman's - Rho meunjukkan nilai $p=$ 0,014 pada taraf signifikansi $\alpha=0,05$, artinya psychology well being (kesejahteraan psikologi) mempunyai hubungan terhadap kepatuhan manajemen diri pasien HD. Sedangkan nilai correlation coefficient menunjukkan angka 0,734. Simpulan: Psychology well being (kesejahteraan psikologi) dan kepatuhan manajemen diri mempunyai keeratan hubungan sebesar $73,4 \%$.
\end{abstract}

Kata kunci: Kepatuhan; manajemen diri; kesejahteraan psikologi

\section{Description of psychological well-being on hemodialysis patient self-management compliance}

\begin{abstract}
Introduction: Hemodialysis is a chronic condition requiring very relevant self-management. Self-management related to poor adherence is a widespread problem in patients on hemodialysis and leads to severe consequences for patients, even death. The purpose of this study was to determine the description of the psychology well being of hemodialysis patients on the compliance of hemodialysis patients with therapy management. Methods: used in this research is descriptive analytic by looking at how the patient's psychological well being and self-management compliance carried out by the patient. The instruments used are Psychological Well Being Questionnaire, Renal Adherence Attitudes Questionnaire (RAAQ) and Renal Adherence Behavior Questionnaire (RABQ). Results: statistical test using Spearman's - Rho showed $p$ value $=0.014$ at significance level $=0.05$, meaning that psychology well being has a relationship with self-management compliance of HD patients. While the correlation coefficient value shows the number 0.734. Conclusions: Psychology well being and self-management compliance have a close relationship of $73.4 \%$.
\end{abstract}

Keywords: Compliance; self-management; psychological well-being

How to Cite: Melastuti, E \& Wahyuningsih, IS. (2021). Gambaran kesejahteraan psikologi terhadap kepatuhan manajemen diri pasien hemodialisa. NURSCOPE: Jurnal Penelitian dan Pemikiran IImiah Keperawatan, 7 (1), 28-37

\section{PENDAHULUAN}

Manajemen dan perawatan penyakit kronis termasuk pasien hemodialisis yang tepat merupakan tantangan yang berkelanjutan dalam perawatan kesehatan. Sampai sejauh ini belum ada obat untuk penyakit kronis, mengendalikan, meminimalkan, atau mengelola efek negatifnya menjadi tujuan utama. 
Dalam perspektif manajemen diri, bukan dokter atau sistem perawatan kesehatan yang harus menyelesaikan sebagian besar manajemen penyakit kronis tetapi pasien sendiri. Manajemen diri terdiri dari dua domain: manajemen diri perawatan kesehatan dan manajemen diri kehidupan sehari-hari. Manajemen diri dari perawatan kesehatan meliputi aktivitas perawatan diri, kemitraan dalam perawatan, komunikasi, self-efficacy perawatan diri, dan kepatuhan. Manajemen diri dari kehidupan sehari-hari berarti mencapai/ mempertahankan "normalitas" dalam peran dan fungsi sehari-hari. (Jonsdottir et al., 2015)

Hemodialisis adalah penyakit kronis yang membutuhkan pengelolaan diri yang sangat relevan. Memahami komponen manajemen diri dapat membantu pasien dan dokter untuk merangkul pendekatan ini, untuk memasuki hubungan timbal balik yang diperlukan, dan untuk memaksimalkan hasil positif bagi pasien dengan hemodialisis (Clark-Cutaia et al., 2018). Manajemen diri oleh pasien berkontribusi pada hasil kesehatan yang lebih baik (Heidari, Fayazi, Borsi, Moradbeigi, \& Nassaji, 2015). Pasien hemodialisis beresiko untuk berbagai komplikasi, mengalami banyak gejala, menjalani diet ketat dan pembatasan cairan, dan harus mematuhi rejimen pengobatan yang kompleks (Clark-Cutaia et al., 2018). Kepatuhan yang buruk merupakan masalah yang luas pada pasien dengan hemodialisis dan menyebabkan konsekuensi berat untuk pasien, bahkan kematian (Ver Halen, Cukor, Constantiner, \& Kimmel, 2012). Ketidakpatuhan obat dapat disengaja atau tidak disengaja. Ketidakpatuhan disengaja terjadi ketika pasien memilih untuk mengabaikan rekomendasi pengobatan dengan menunda, atau kehilangan dosis obat yang diresepkan (Ghimire, Castelino, Lioufas, Peterson, \& Zaidi, 2015). Ketidakpatuhan yang tidak disengaja, adalah kurangnya pemahaman, kelupaan atau komunikasi dengan penyedia layanan kesehatan (Ghimire, Castelino, Jose, \& Zaidi, 2017; Griva et al., 2014), memperpanjang waktu untuk terapi dialisis (Park, 2018; Xie et al., 2016). Dalam kasus hemodialisis, tujuan ini sebagian besar tidak dapat dicapai tanpa manajemen diri pasien yang aktif dan komprehensif dari semua aspek kehidupan (Park, 2018; Xie et al., 2016).

Dewasa ini hemodialisis dilandasi tiga praktik dasar dan komplementer untuk memberikan perawatan yang berkualitas yang meliputi: 1) rujukan awal, 2) pasien sebagai fokus edukasi dan 3) interdisipliner tim (Barthelemy et al., 2015). Interdisipliner tim ini sangat penting karena hemodialisis memerlukan serangkaian tuntutan fisik, sosial dan emosional yang kompleks sebagai hasil dari persepsi penyakit sebagai ancaman yang mampu memberikan keterampilan mengatasi coping pasien dan sebagai penyedia layanan kesehatan. Dimensi emosional dan biologis keduanya penting dalam psikologi kesehatan pada umumnya dan dalam perawatan kesehatan nefrologi pada khususnya (Adequacy, Adequacy, \& Access, 2006).

Berdasarkan interview dan observasi yang dilakukan pada tanggal 27 September 2018 di Unit Hemodialisis Rumah Sakit Islam Sultan Agung Semarang pasien pada 108 ESRD yang menjalani hemodialisis didapatkan data bahwa 52 pasien dari 108 pasien atau (48\%) tidak patuh terhadap asupan cairan dan mengalami komplikasi intra dialysis yaitu sesak nafas, hipertensi, hipotensi dan oedema . Alasan pasien (100\%) adalah haus dan mulut kering sehingga mereka tidak bisa menahan diri untuk minum air lebih dari yang dianjurkan (Pasien Hemodialisis, 2020).

Upaya yang dilakukan rumah sakit selama untuk meningkatkan kepatuhan pasien selama ini adalah dengan memberikan pendidikan kesehatan. Berdasarkan hasil interview dengan kepala ruang/ unit hemodialisis yang dilakukan pada tanggal 18 Januari 2020 pendidikan kesehatan di ruang hemodialisis Rumah Sakit Islam Sultan Agung Semarang masih mempergunakan metoda konvensional, dengan media leaflet, dilaksanakan perindividu oleh perawat pada saat awal terdiagnosa ESRD dan harus menjalani HD. Evaluasi terstruktur tentang kemampuan pasien dalam melaksanakan kepatuhan tersebut belum pernah 
dilakukan oleh pihak rumah sakit. Berdasarkan kondisi tersebut mengetahui gambaran psikologi well being diakitkan dengan kepatuhan pada pasien hemodialisis adalah hal penting yang harus dilakukan, dengan psikologi well being yang baik maka pasien akan menjalani managemen terapi dengan baik sehingga kondisi pasien bisa dipertahankan dan tidak jatuh kekadaan yang semakin memburuk/ komplikasi dan tidak mengalami kodisi gawat darurat .

Kesejahteraan psikologis berkaitan dengan bagaimana individu mengevaluasi pemenuhan dalam kehidupan mereka di seluruh domain kehidupan rumah, sekolah, mengelola situasi, dan bertemu dengan orang-orang (Mann \& Ridder, 2013). Perspektif ini mirip dengan karya awal ( Ryff 's no date) yang menyediakan perspektif multi-dimensi kesejahteraan psikologis. Aspek multi-dimensi ini meliputi tujuan hidup, pertumbuhan pribadi, hubungan positif dengan orang lain, penguasaan lingkungan, penerimaan diri, dan otonomi (Gerogianni \& Babatsikou, 2014). Penelitian menunjukkan bahwa kesejahteraan psikologis terkait dengan pengaruh positif (Urry et al., 2004), yang didefinisikan sebagai respons yang menyenangkan terhadap lingkungan termasuk antusiasme dan kewaspadaan (Mitchell, Eby, \& Lorys, 2014). Dalam sebuah penelitian yang dilakukan oleh (D'Onofrio et al., 2017) kesejahteraan psikologis (diindikasikan sebagai sumber daya) dan pengaruh positif ditemukan untuk memprediksi olahraga teratur, lebih sedikit merokok, peningkatan tidur, dan lebih sedikit gejala psikosomatik. Sejauh ini belum ada penelitian tentang dampak psychology well being (kesejahteraan psikologi) terkait kepatuhan, maka harus ada upaya yang dilakukan untuk mengetahui psikologi well being pasien hemodilaisis dan kepatuhan. Tujuan dari penelitian ini adalah untuk mengetahui gambaran Psychology well being pasien hemodialisis dalam rangka mempromosikan kepatuhan manajemen terapi pasien hemodialisis.

\section{METODE}

Jenis penelitian yang digunakan adalah kuntitatif analitik dengan pendekatan cross sectional, Populasi dalam penelitian ini adalah seluruh pasien hemodialisis di RSISA Semarang Pengambilan sampel penelitian dilakukan secara concecutive sampling. Besar sampel ditentukan dari keseluruhan pasien hemodialisi yang memenuhi kriteria inklusi dan ekslusi. Kriteria yang ditetapkan yaitu : kriteria inklusi : 1) Pasien hemodialisis yang berusia 18-45 tahun. 2) Mampu berbahasa Indoesia, menulis bahasa Indonesia dan komunikatif. 3) Pasien yang menjalani hemodialisi 2 kali semingu dalam kurun waktu kurang dari 3 bulan, kriteria ekslusi : 1) Pasien sedang berada dalam kondisi gawat darurat. 2) Pasien yang menjalani hemodialisis cito . 3) Pasien menolak menjadi responden

Didapatkan sampel berjumlah 130 orang. Alat pengumpulan data yang digunakan dalam penelitian ini adalah sebagai berikut : Lembar Observasi yang bertuliskan data demografi responden usia dan jenis kelamin, Pendidikan, pekerjaan, lama menjalani hemodialisis, kadar hemoglobin, lembar kuesioner untuk menilai Kepatuhan Manajemen diri Instrumen yang digunakan adalah Renal Adherence Attitudes Questionnaire (RAAQ): RAAQ (Rushe \& Mcgee, 1998) dan Renal Adherence Behaviour Questionnaire (RABQ) (Rushe \& Mcgee, 1998), lembar kuesioner untuk menilai kesejahteraan psikologi dengan mengunakan Psychology Well Being Questionare (Burns \& Machin, 2009). Uji normalitas data menggunakan Kolmogorov Sminrov Test, analisis bivariat menggunakan uji Spearman's - Rho 


\section{PEMBAHASAN}

Tabel 1. Deskripsi Faktor Karakteristik Responden di Ruang HD Rumah Sakit Islam Sultan Agung Bulan Desember Tahun 2020 ( $n=130)$.

\begin{tabular}{|c|c|c|c|}
\hline Faktor Karakteristik & Kategori & $f$ & $\%$ \\
\hline \multirow[t]{6}{*}{ Usia } & 18-25 Tahun & 4 & 3,1 \\
\hline & 26-35 Tahun & 6 & 4,6 \\
\hline & 36-45 Tahun & 28 & 21,5 \\
\hline & 46-55 Tahun & 54 & 41,5 \\
\hline & 56-65 Tahun & 33 & 25,4 \\
\hline & $>65$ Tahun & 5 & 3,8 \\
\hline \multicolumn{2}{|l|}{ Total } & 130 & 100 \\
\hline \multirow[t]{2}{*}{ Jenis Kelamin } & Laki-laki & 50 & 38,5 \\
\hline & Perempuan & 80 & 61,5 \\
\hline \multicolumn{2}{|l|}{ Total } & 130 & 100 \\
\hline \multirow[t]{3}{*}{ Pendidikan } & Dasar & 17 & 13,1 \\
\hline & Menengah & 90 & 69,2 \\
\hline & Tinggi & 23 & 17,7 \\
\hline \multicolumn{2}{|l|}{ Total } & 130 & 100 \\
\hline \multirow{3}{*}{ Status Pernikahan } & Belum Menikah & 9 & 6,9 \\
\hline & Menikah & 112 & 86,2 \\
\hline & Janda/Duda & 9 & 6,9 \\
\hline \multicolumn{2}{|l|}{ Total } & 130 & 100 \\
\hline \multirow[t]{2}{*}{ Pekerjaan } & Tidak Bekerja & 53 & 40,8 \\
\hline & Bekerja & 77 & 59,2 \\
\hline \multicolumn{2}{|l|}{ Total } & 130 & 100 \\
\hline \multirow[t]{2}{*}{ Pendapatan } & $\leq$ UMR & 64 & 49,2 \\
\hline & $>$ UMR & 66 & 50,8 \\
\hline \multicolumn{2}{|l|}{ Total } & 130 & 100 \\
\hline \multirow[t]{2}{*}{ Kadar Hb } & Anemia & 50 & 38,5 \\
\hline & Tidak Anemia & 80 & 61,5 \\
\hline Total & & 130 & 100 \\
\hline
\end{tabular}

Pada tabel 1 dapat dilihat bahwa bahwa pada indikator usia porsi terbanyak adalah usia 46-55 (41,5\%), jenis kelamin porsi terbanyak adalah perempan (61,5\%), pendidikan porsi terbanyak adalah pendidikan tingkat menengah $(69,2 \%)$, status pernikahan porsi terbanyak adalah menikah $(86,2 \%)$, pekerjaan porsi vtebanyak adalah kategori bekerja $(59,2 \%)$, pendapatan porsi terbanyak adalah kategori > UMR $(50,8 \%)$, pada kadar $\mathrm{Hb}$ masih banyak ditemukan kategori anemia $(38,5 \%)$.

Deskripsi Variabel

Kesejahteraan psikologi pasien HD

Tabel 2. Distribusi Frekuensi Kesejahteraan Psikologi Pasien HD di RSISA Semarang Bulan Desember Tahun 2020.

\begin{tabular}{cccc}
\hline \multirow{2}{*}{ Kesejahteraan Psikologi } & \multicolumn{3}{c}{ Frekuensi } \\
\cline { 2 - 4 } & $\mathbf{n}$ & \% \\
\hline Rendah & 21 & 16,2 \\
Sedang & 87 & 66,9 \\
Tinggi & 22 & 16,9 \\
\hline
\end{tabular}




\begin{tabular}{cccc}
\hline \multirow{2}{*}{ Kesejahteraan Psikologi } & \multicolumn{2}{c}{ Frekuensi } \\
\cline { 2 - 4 } & $\mathbf{n}$ & \% \\
\hline Total & 130 & 100 \\
\hline
\end{tabular}

Tabel 2 menunjukkan bahwa sebagian besar (66,9\%) responden mempunyai phscycology wellbeing (kesejahteraan psikologi) yang masuk dalam kategori sedang, sebagian kecilnya $(16,9 \%)$ mempunyai kesejahteraan psikologi yang tinggi, dan sisanya $(16,2 \%)$ mempunyai kesejahteraan psikologi yang rendah. Komponen kesejahteraan psikologis meliputi otonomi, pengembangan diri, penguasaan lingkungan,tujuan dalam hidup, hubungan positif dengan orang lain, penerimaan diri

Kepatuhan manajemen diri pasien HD

Tabel 3. Distribusi Frekuensi Kepatuhan Manajemen Diri Pasien HD di RSISA Semarang Bulan Desember Tahun 2020.

\begin{tabular}{ccc}
\hline \multirow{2}{*}{ Kepatuhan Manajemen Diri } & \multicolumn{2}{c}{ Frekuensi } \\
\cline { 2 - 3 } & $\mathbf{n}$ & $\mathbf{\%}$ \\
\hline Tidak Patuh & 64 & 49,2 \\
Patuh & 66 & 50,8 \\
\hline Total & 130 & 100 \\
\hline
\end{tabular}

Tabel 3 menunjukkan bahwa lebih dari setengah responden $(50,8 \%)$ patuh terhadap pengelolaan manajemen diri pasien hemodialisis, dan sisanya $(49,2 \%)$ tidak patuh terhadap penegelolaan manajemen diri pasien hemodialisis.

Hubungan antara psychology well being (kesejahteraan psikologi) dengan kepatuhan manajemen diri pasien HD di RSISA Semarang dapat dillihat pada tebel berikut:

Tabel 1. Tabulasi silang antara psychology well being (kesejahteraan psikologi) dan kepatuhan manajemen diri pasien HD di RSISA Semarang Bulan Desember Tahun 2020.

\begin{tabular}{|c|c|c|c|c|c|c|}
\hline \multirow{3}{*}{ Kesejahteraan Psikologi } & \multicolumn{4}{|c|}{ Kepatuhan Manajemen Diri } & \multirow{2}{*}{\multicolumn{2}{|c|}{ Total }} \\
\hline & \multicolumn{2}{|c|}{ Tidak Patuh } & \multicolumn{2}{|c|}{ Patuh } & & \\
\hline & $\mathrm{n}$ & $\%$ & $\mathrm{n}$ & $\%$ & $\mathrm{n}$ & $\%$ \\
\hline Rendah & 17 & 81 & 4 & 19 & 21 & 100 \\
\hline Sedang & 42 & 48,3 & 45 & 51,7 & 87 & 100 \\
\hline Tinggi & 5 & 22,7 & 17 & 77,3 & 22 & 100 \\
\hline Spearman's-Rho & orrel & 0,734 & & & & \\
\hline
\end{tabular}

Hasil uji statistik menggunakan Spearman's - Rho meunjukkan nilai $p=0,014$ pada taraf signifikansi $\alpha=$ 0,05 , artinya psychology well being (kesejahteraan psikologi) mempunyai hubungan terhadap kepatuhan manajemen diri pasien HD di RSISA Semarang. Sedankan nilai correlation coefficient menunjukkan angka 0,734 yang artinya psychology well being (kesejahteraan psikologi) dan kepatuhan manajemen diri mempunyai keeratan hubungan sebesar $73,4 \%$.

Berdasarkan data yang diperoleh dari 130 responden sebanyak 16,9\% atau 22 orang responden menunjukkan psychological well-being yang tinggi. Hal ini menunjukkan bahwa responden yang memiliki psychological well-being yang tinggi pada umumnya mampu menggunakan potensi yang dimilikinya 
dalam menghadapi penyakit yang dideritanya, yang mana pasien HD mampu menyesuaikan diri dan merasa nyaman dengan kondisinya saat ini dan bersikap positif terhadap masa lalunya dengan cara memperbaiki diri, responden memiliki kepedulian dengan responden lainnya dengan saling menanyakan kabar, merasa bahwa dirinya berkembang dari waktu ke waktu, memiliki tujuan dan makna hidup, mampu mengatur aktivitas dan tanggung jawab sehari-hari sehingga merasa nyaman dengan lingkungan tempat tinggalnya, serta mampu memberikan penilaian terhadap dirinya dengan standar nilai pribadi (Vázquez, Hervás, Rahona, \& Gómez, 2009).

Psychological well-being yang tinggi yang dimiliki oleh seorang inividu akan menyebabkan seorang individu yang merasa puas dengan hidupnya, memiliki kondisi emosional yang positif, serta mampu melewati pengalaman-pengalaman buruk yang bisa menghasilkan suatu kondisi emosional yang negatif, ada hubungan yang positif dengan lingkungan dan orang lain, serta mampu menentukan nasibnya sendiri secara mandiri, memiliki tujuan hidup dan arti hidup yang jelas, mampu mengontrol kondisi lingkungan sekitar, serta adanya kemampuan mengembangkan diri sendiri (Ryff, 1989). Didefinisikan oleh (Sagone \& Caroli, 2014; Santos, 2010) bahwa psychological well-being sebagai bentuk dorongan untuk menggali potensi diri individu secara menyeluruh. Dorongan tersebut bisa mengakibatak seseorang menjadi pasrah terhadap keadaan yang menjadikan psychological well-being individu menjadi rendah atau individu berusaha untuk memperbaiki kehidupannya dimana hal ini membuat psychological well-being individu tersebut menjadi lebih tinggi.

Berdasarkan hasil uji statistik hubungan antara psychology well being (kesejahteraan psikologi) dengan kepatuhan manajemen diri pasien HD dengan menggunakan uji Spearmen dapat disajikan temuan tentang tabulasi silang antara psychology well being (kesejahteraan psikologi) dan kepatuhan manajemen diri pasien HD di RSISA Semarang, serta dilengkapi dengan nilai signifikansi uji Spearman's - Rho. Hasil uji silang menggambarkan bahwa dari seluruh responden yang mempunyai kesejahteraan psikologi rendah, hampir seluruhnya (81\%) tidak patuh terhadap pengelolaan manajemen diri. Dari seluruh pasien yang mempunyai kesejahteraan psikologi sedang, lebih dari setengahnya $(51,7 \%)$ patuh terhadap pengelolaan manajemen diri. Sedangkan dari seluruh pasien yang mempunyai kesejahteraan psikologi tinggi, sebagian besar $(77,3 \%)$ patuh terhadap pengelolaan manajemen diri.

Hasil uji statistik menggunakan Spearman's - Rho meunjukkan nilai $p=0,014$ pada taraf signifikansi $\alpha=$ 0,05 , artinya psychology well being (kesejahteraan psikologi) mempunyai hubungan terhadap kepatuhan manajemen diri pasien HD di RSISA Semarang. Sedankan nilai correlation coefficient menunjukkan angka 0,734 yang artinya psychology well being (kesejahteraan psikologi) dan kepatuhan manajemen diri mempunyai keeratan hubungan sebesar 73,4\%. Menurut (Clark, Farrington, \& Chilcot, 2014; Masood, Kamran, Rashid, \& Mazahir, 2017), individu yang memiliki level subjective well-being yang tinggi, umumnya memiliki sejumlah kualitas yang mengagumkan. Pada individu dengan level ini lebih mampu mengontrol emosi serta mampu menghadapi banyak peristiwa dalam hidup dengan lebih baik lagi. Sedangkan individu yang memiliki level subjective well- being yang rendah, akan memandang rendah hidup serta menganggap peristiwa yang terjadi adalah hal yang tidak menyenangkan dan akan menimbulkan keadaan emosi yang tidak menyenangkan seperti kemarahan, depresi serta kecemasan (Clark et al., 2014; Masood et al., 2017)

\section{SIMPULAN DAN SARAN}

Pada karakteristik responden didapatkan hasil pada usia porsi terbanyak adalah usia $46-55$ (41,5\%), jenis kelamin porsi terbanyak adalah perempan (61,5\%), pendidikan porsi terbanyak adalah pendidikan tingkat 
menengah $(69,2 \%)$, status pernikahan porsi terbanyak adalah menikah $(86,2 \%)$, pekerjaan porsi tebanyak adalah kategori bekerja $(59,2 \%)$, pendapatan porsi terbanyak adalah kategori > UMR (50,8\%), pada kadar $\mathrm{Hb}$ masih banyak ditemukan kategori anemia $(38,5 \%)$,

\section{DAFTAR PUSTAKA}

Ryff' s Psychological Well-Being Scales ( PWB ), 42 Item version Please indicate your degree of agreement ( using a score ranging from 1-6) to the following. (n.d.), 3-5.

Adequacy, H., Adequacy, P. D., \& Access, V. (2006). 2006 Updates Clinical Practice Guidelines. Blood Pressure, 33(5), 487-488. https://doi.org/10.1053/j.ajkd.2006.04.040

Anding, K., Bär, T., Trojniak-hennig, J., Kuchinke, S., Krause, R., Rost, J. M., \& Halle, M. (2015). A structured exercise programme during haemodialysis for patients with chronic kidney disease : clinical bene fi t and long-term adherence, (3), 1-9. https://doi.org/10.1136/bmjopen-2015-008709

Azam, M. (2018). Factors Associated with Chronic Kidney Disease Incidence among Patients with Hypertension in Indonesia GINJAL KRONIK PADA PENDERITA HIPERTENSI DI INDONESIA Factors Associated with Chronic Kidney Disease Incidence among Patients with Hypertension in Indone. MKMI, 13(January), 319-328.

Barberis, N., Cernaro, V., Costa, S., Montalto, G., Lucisano, S., Larcan, R., \& Buemi, M. (2017). The relationship between coping, emotion regulation, and quality of life of patients on dialysis. The International Journal of Psychiatry in Medicine, 52(2), 111-123. https://doi.org/10.1177/0091217417720893

Barthelemy, A., Lobbedez, T., Bechade, C., Henri, P., Eric, J. B., Alain, C., \& Isabelle, J. (2015). Hemodialysis in satellite dialysis units: incidence of patient fallback to the in-center dialysis unit, 485-493. https://doi.org/10.1007/s40620-014-0153-1

Bayoumi, M., Harbi, A. Al, Suwaida, A. Al, Ghonaim, M. Al, Wakeel, J. Al, \& Mishkiry, A. (2013). of Kidney Diseases and Transplantation Original Article Predictors of Quality of Life in Hemodialysis Patients. Security, 24(2), 254-259.

Bonner, A., Havas, K., Douglas, C., Thepha, T., Bennett, P., \& Clark, R. (2014). Self-management programmes in stages 1-4 chronic kidney disease: A literature review. Journal of Renal Care, 40(3), 194-204. https://doi.org/10.1111/jorc.12058

Burns, R. A., \& Machin, M. A. (2009). Investigating the structural validity of Ryff's psychological well-being scales across two samples. Social Indicators Research, 93(2), 359-375. https://doi.org/10.1007/s11205-008-9329-1

Chang, T. Y., Zhang, Y. L., Shan, Y., Liu, S. S., Song, X. Y., Li, Z. Y., ... Gao, D. (2018). A study on the information-motivation-behavioural skills model among Chinese adults with peritoneal dialysis. Journal of Clinical Nursing, 27(9-10), 1884-1890. https://doi.org/10.1111/jocn.14304

Clark-Cutaia, M. N., Sevick, M. A., Thurheimer-Cacciotti, J., Hoffman, L. A., Snetselaar, L., Burke, L. E., \& 
Zickmund, S. L. (2018). Perceived Barriers to Adherence to Hemodialysis Dietary Recommendations. Clinical Nursing Research, 1-21. https://doi.org/10.1177/1054773818773364

Clark, S., Farrington, K., \& Chilcot, J. (2014). Nonadherence in dialysis patients: Prevalence, measurement, outcome, and psychological determinants. Seminars in Dialysis, 27(1), 42-49. https://doi.org/10.1111/sdi.12159

Corwin, E. J. (2009). Buku Saku Patofisiologi. Jakarta: EGC.

Curtin, R. B., Sitter, D. C. B., Schatell, D., \& Chewning, B. A. (2004). Self-management, knowledge, and functioning and well-being of patients on hemodialysis. Nephrology Nursing Journal : Journal of the American Nephrology Nurses' Association, 31(4).

D’Onofrio, G., Simeoni, M., Rizza, P., Caroleo, M., Capria, M., Mazzitello, G., ... Fuiano, G. (2017). Quality of life, clinical outcome, personality and coping in chronic hemodialysis patients. Renal Failure, 39(1), 45-53. https://doi.org/10.1080/0886022X.2016.1244077

Gerogianni, S. K., \& Babatsikou, F. P. (2014). Psychological aspects in treatment of chronic renal failure. Social Science \& Medicine (1967), 8(2), 205-214. https://doi.org/10.1016/0037-7856(68)90007-3 Ghimire, S., Castelino, R. L., Jose, M. D., \& Zaidi, S. T. R. (2017). Medication adherence perspectives in haemodialysis patients: a qualitative study. BMC Nephrology, 18(1), 1-9. https://doi.org/10.1186/s12882-017-0583-9

Ghimire, S., Castelino, R. L., Lioufas, N. M., Peterson, G. M., \& Zaidi, S. T. R. (2015). Nonadherence to medication therapy in haemodialysis patients: A systematic review. PLOS ONE, 10(12), 1-19. https://doi.org/10.1371/journal.pone.0144119

Griva, K., Lai, A. Y., Lim, H. A., Yu, Z., Foo, M. W. Y., \& Newman, S. P. (2014). Non-adherence in patients on peritoneal dialysis: A systematic review. PLOS ONE, 9(2). https://doi.org/10.1371/journal.pone.0089001

Heidari, M., Fayazi, S., Borsi, H., Moradbeigi, K., \& Nassaji, N. A. (2015). Effect of a self-management program based on $5 \mathrm{~A}$ model on dyspnea and fatigue severity among patients with chronic obstructive pulmonary disease: A randomized clinical trial. HAYAT, 20(4), 89-99. Retrieved from https://www.scopus.com/inward/record.uri?eid=2-s2.0-

84925011203\&partnerID=40\&md5=57dcc25f819995299067e46792cfc1bb

Jonsdottir, H., Amundadottir, O. R., Gudmundsson, G., Halldorsdottir, B. S., Hrafnkelsson, B., Ingadottir, T. S., ... Stefansdottir, I. K. (2015). Effectiveness of a partnership-based self-management programme for patients with mild and moderate chronic obstructive pulmonary disease: A pragmatic randomized controlled trial. Journal of Advanced Nursing, 71(11), 2634-2649. https://doi.org/10.1111/jan.12728

Joyce M. Black, J. H. H. (2014). Keperawatan Medikal Bedah: Manajemen Klinis Untuk Hasil yang Diharapkan (8th ed.). Singapura: Elsevier Inc.

Lita, P. (2013). Hubungan Tingkat Kecemasan dengan Mekanisme Koping pada Pasien dengan Gagal Ginjal yang Menjalani Hemodialisa di RS PKU Muhammadiyah Yogyakarta. Naskah Publikasi, 
4.

Logani, I., Tjitrosantoso, H., \& Yudistira, A. (2017). Faktor Risiko Terjadinya Gagal Ginjal Kronik Di RSUP PROF. DR. R. D. KANDOU MANADO. Pharmacon, 6(3), 128-136.

Mann, T., \& Ridder, D. De. (2013). Self-Regulation of Health Behavior: Social Psychological Approaches to Goal Setting and Goal Striving, 32(5), 487-498. https://doi.org/10.1037/a0028533

Masood, A., Kamran, F., Rashid, S., \& Mazahir, S. (2017). Life-orientation, subjective well-being and social support as predictors of quality of life in patients with end stage renal disease. Bangladesh Journal of Medical Science, 16(3), 346-353. https://doi.org/10.3329/bjms.v16i3.32845

Meng, X., \& D'Arcy, C. (2016). Coping strategies and distress reduction in psychological well-being? A structural equation modelling analysis using a national population sample. Epidemiology and Psychiatric Sciences, 25(4), 370-383. https://doi.org/10.1017/S2045796015000505

Mikhali, A., Brown, C., Williams, J. A., Mathrani, V., Shrivastava, R., Evans, J., ... Bhandari, S. (2017). Clinical Practice Guideline Anaemia of Chronic Kidney Disease. Anaemia of Chronic Kidney Disease, (June). Retrieved from www.nice.org.uk/accreditation

Nursalam. (2017). Metodologi Penelitian Ilmu Keperawatan. Jakarta: Salemba Medika.

Park, S. K. (2018). Trajectories of change in cognitive function in people with chronic obstructive pulmonary disease. Journal of Clinical Nursing, 27(7-8), 1529-1542. https://doi.org/10.1111/jocn.14285

PERNEFRI. (2011). 4 th Report Of Indonesian Renal Registry 20114 th Report Of Indonesian Renal Registry 2011, 13-15.

Rice, S. A. . L. M. W. (2005). Patofisiologi : Konsep Klinis Proses-Proses Penyakit (6th ed.). Jakarta: EGC. Rostanti, A., Bawotong, J., \& Onibala, F. (2016). Faktor-Faktor yang berhubungan dengan kepatuhan menjalani terapi hemodialisa pada Penyakit Ginjal Kronik di Ruang Dahlia dan Melati RSUP Prof. Dr. R. D. Kandou Manado, Jurnal Keperawatan, 4(2)

Rushe, H., \& Mcgee, H. M. (1998). Assessing adherence to dietary recommendations for hemodialysis patients: The Renal Adherence Attitudes Questionnaire (RAAQ) and the Renal Adherence Behaviour Questionnaire (RABQ). Journal of Psychosomatic Research, 45(2), 149-157. https://doi.org/10.1016/S0022-3999(97)00228-6

Ryff, C. D. (1989). Happiness is everything, or is it? Explorations on the meaning of psychological wellbeing. Journal of Personality and Social Psychology, 57(6), 1069-1081. https://doi.org/10.1037/0022-3514.57.6.1069

Sagone, E., \& Caroli, M. E. De. (2014). Relationships between Psychological Well-being and Resilience in Middle and Late Adolescents. Procedia - Social and Behavioral Sciences, 141, 881-887. https://doi.org/10.1016/j.sbspro.2014.05.154

Salvador, Mestre, Soler, Pascual-benito L, Alonso, P. (2017). Chronic kidney disease in hypertensive subjects $\geq 60$ years treated inPrimary Care. The Research Group of the MARREC-HTA Project, 1-9. 
Santos, P. R. (2010). Subjective Well-Being Measures of Hemodialysis Patients.

Silva, L. F., Lopes, G. B., Cunha, T. O., Protásio, B. M., Pisoni, R. L., James, S. A., \& Lopes, A. A. (2014). Coping with fluid restriction and the quality of life in hemodialysis patients with very low or no daily urine output. International Journal of Artificial Organs, 37(6), 427-435. https://doi.org/10.5301/ijao.5000329

Smeltzer, S. C. (2002). Buku ajar keperawatan medikal bedah. Jakarta: EGC.

Sudoyo, A. W., Setiyohadi, B., Alwi, I., Simadibrata, M., \& Setiati, S. (2009). Buku Ajar Ilmu Penyakit Dalam (II). Jakarta: Interna Publishing.

Suzzane C. Smeltzer, Brenda G. Bare, Janice L. Hinkle, K. H. C. (2006). Brunner and Suddarth's Textbook of Medical Surgical Nursing (11th ed.). Philladelphia: Lippincott Williams and Wilkins.

Tsang, W. T., \& Wang, S. (2015). Faktor Risiko Gagal Ginjal Kronik Di Unit Hemodialisis Rsud Wates Kulon Progo. Applied Physics Letters, 25(7), 415-418. https://doi.org/10.1063/1.1655531

Vázquez, C., Hervás, G., Rahona, J. J., \& Gómez, D. (2009). Psychological well-being and health. Contributions of positive psychology. And Health Psychology, 5, 15-27.

Ver Halen, N., Cukor, D., Constantiner, M., \& Kimmel, P. L. (2012). Depression and mortality in end-stage renal disease. Current Psychiatry Reports, 14(1), 36-44. https://doi.org/10.1007/s11920-0110248-5

Xie, H., Cheng, C., Tao, Y., Zhang, J., Robert, D., Jia, J., \& Su, Y. (2016). Quality of life in Chinese family caregivers for elderly people with chronic diseases. Health and Quality of Life Outcomes, 14(1), 19. https://doi.org/10.1186/s12955-016-0504-9

Zimbudzi, E., Lo, C., Misso, M. L., Ranasinha, S., Kerr, P. G., Teede, H. J., \& Zoungas, S. (2018). Effectiveness of self-management support interventions for people with comorbid diabetes and chronic kidney disease: A systematic review and meta-analysis. Systematic Reviews, 7(1). https://doi.org/10.1186/s13643-018-0748-z 